\title{
geografiar
} Malaysian Journal of Society and Space

\section{Ketersampaian penduduk terhadap perkhidmatan pengangkutan awam di Bandaraya Kota Kinabalu, Sabah}

\author{
Saravanan Sundara Sakaran ${ }^{1}$, Harifah Mohd Noor ${ }^{1}$, Rosmiza M. Z. ${ }^{2}$ \\ ${ }^{1}$ Program Geografi, Fakulti Kemanusiaan, Seni dan Warisan, Universiti Malaysia Sabah \\ ${ }^{2}$ Program Geografi, Pusat Kajian Pembangunan, Sosial dan Persekitaran (SEEDS), \\ Fakulti Sains Sosial dan Kemanusiaan, Universiti Kebangsaan Malaysia \\ Correspondence: Saravanan Sundara Sakaran (email: saravanan875id1 @ gmail.com)
}

Received: 24 May 2019; Accepted: 21 July 2019; Published: 27 February 2020

\begin{abstract}
Abstrak
Ketersampaian merujuk kepada kemudahan untuk menuju ke sesuatu destinasi menerusi penggunaan pelbagai mod pengangkutan. Salah satunya adalah pengangkutan awam. Namun mod ini seringkali dikaitkan dengan ketidak berkesanannya seperti laluan perkhidmatan yang tidak menyeluruh terhadap beberapa laluan. Kajian ini bertujuan mengenal pasti faktor yang mempengaruhi ketersampaian perkhidmatan pengangkutan awam (bas awam) di Bandaraya Kota Kinabalu. Kaedah kajian menggunakan data primer menerusi pemerhatian langsung terhadap perkhidmatan bas awam di beberapa laluan utama ke pusat Bandaraya. Beberapa sesi temu bual diadakan bersama agensi kerajaan dan pengusaha bas serta satu set borang kaji selidik diedarkan kepada 274 responden menerusi kaedah pensampelan bertujuan. Kajian ini menggunakan analisis deskriptif seperti frekuensi, peratusan dan nilai skor min dengan menggunakan alat analisis Statistical Packages for the Social Sciences (SPSS). Hasil kajian menunjukkan terdapat beberapa jalan utama yang menghala ke pusat bandar tidak menerima perkhidmatan bas awam. Tiga faktor yang menyumbang kepada perkhidmatan laluan bas iaitu faktor pengusaha bas, faktor permintaan penduduk dan faktor Pihak Berkuasa Tempatan. Menerusi skor min purata menunjukkan faktor pengusaha bas adalah faktor tertinggi terhadap perkhidmatan laluan yang tidak menyeluruh, diikuti oleh faktor penduduk dan faktor Pihak Berkuasa Tempatan. Penemuan ini dapat membantu Pihak Berkuasa Tempatan serta beberapa agensi berkaitan untuk merangka dan merancang polisi perkhidmatan bas awam yang lebih menyeluruh kepada penduduk khususnya di Bandaraya Kota Kinabalu.
\end{abstract}

Kata kunci: ketersampaian, Kota Kinabalu, laluan, pengangkutan awam, penduduk, pengusaha bas 


\title{
Residents' accessibility to public transportation services in Kota Kinabalu City, Sabah
}

\begin{abstract}
Accessibility is the convenience of getting to a destination that uses multiple modes of transportation. One example of such mode is the public transportation. However, the public transportation is often associated with inefficiencies such as incomplete service routes. This study identifies factors that influence the accessibility of public transportation (public buses) services in Kota Kinabalu city. The study used primary data through direct observation of public buses services on several major routes to the city center. Several interview sessions were held with government agencies and bus operators and a set of survey forms were distributed to 274 respondents through the purposive sampling method. This study uses descriptive analysis such as frequency, percentage and mean values using the Statistical Packages for the Social Sciences (SPSS). The results show that there are several main roads to the city center, where there is no public buses service. The three factors contributing to the buses route services are the bus operators, the demand from resident's factors and the Local Authority factors. The average mean score indicates that the bus operator factor is the highest factor for overall route services (average mean $=3.01$ ) followed by resident's factor (average mean $=2.90$ ) and Local Authority factor (average mean $=2.83$ ). These findings help the Local Authorities and some relevant agencies to design and planning a more comprehensive public buses service policy for residents in Kota Kinabalu city.
\end{abstract}

Keywords: accessibility, Kota Kinabalu, routes, public transportation, residents, bus operator

\section{Pengenalan}

Ketersampaian merupakan sesuatu perkara yang amat penting dalam usaha untuk membolehkan penduduk sampai ke suatu destinasi untuk mendapatkan sesuatu keperluan dan menjalankan sesuatu aktiviti sosial. Ketersampaian adalah matlamat utama dalam perkhidmatan sesuatu pengangkutan termasuk pengangkutan awam. Perspektif ini menganggap terdapat pelbagai cara untuk menambah baik pengangkutan awam, termasuk mobiliti dan pengurusan guna tanah yang lebih baik dengan mengurangkan jarak di antara destinasi (Litman, 2013).

Ketersampaian jaringan sistem pengangkutan awam yang bersifat efisien amat diperlukan dalam kehidupan sesebuah masyarakat untuk membolehkan suatu aktiviti sosial dapat dijalankan dengan jayanya. Hal ini kerana ia penting dalam meningkatkan akses perhubungan antara satu tempat dengan tempat yang lainnya. Dalam hal ini akan memudahkan penduduk untuk melaksanakan sesuatu pekerjaan ataupun sesuatu aktiviti dengan jayanya (Rancangan Malaysia Kesebelas 11, RMK 11). Antara kandungan dalam Rancangan Malaysia Kesebelas adalah menyediakan peluang kepada rakyat Malaysia untuk menyediakan kemudahan mengakses pengangkutan awam yang lebih sistematik dalam usaha meningkatkan sistem jaringan dan perhubungan yang mudah dan selamat.

Sasaran kerajaan Malaysia adalah untuk terus menyediakan akses kepada pengangkutan awam yang mencukupi dan mampu dibayar. Langkah ini adalah bagi membolehkan pergerakan barangan dan penumpang yang selamat, cekap dan cepat, terutamanya merentasi bandar dan luar bandar sebagaimana yang dirancang dalam RMK 11 . Terdapat beberapa kepentingan pengangkutan awam kepada penduduk seperti menyediakan 
kemudahan mobiliti bagi seseorang yang tiada pengangkutan persendirian, mengelakkan kesesakan jalan raya, menjaga kelestarian alam sekitar dan fleksibiliti kepada penumpangnya (White, 2002). Mod pengangkutan awam yang dominan digunakan di negara-negara membangun dalam pengangkutan darat ialah bas secara konvensional. Ini kerana bas merupakan satu-satunya pengangkutan awam yang mampu milik dalam kalangan golongan miskin bandar (Armstrong \& Sebastian, 1987). Oleh itu, artikel ini bertujuan membincangkan dan meneliti faktor-faktor yang mempengaruhi ketersampaian perkhidmatan bas awam di beberapa laluan utama menuju ke pusat Bandaraya Kota Kinabalu, Sabah.

\section{Kajian literatur}

\section{Konsep ketersampaian}

Konsep ketersampaian pengangkutan awam merupakan satu konsep yang membawa pelbagai maksud (Jadual 1). Secara umumnya dapat dirumuskan bahawa konsep ketersampaian pengangkutan awam merupakan satu peluang kepada penduduk untuk melibatkan diri dalam aktiviti sosial harian seperti pekerjaan, pendidikan dan aktiviti sosial lain misalnya membeli belah, rekreasi, hiburan seperti mana dijelaskan oleh Handy (1994); Couclelis (2000); Carruthers et al. (2005); Abreha (2007); Litman (2013); Wee (2016). Oleh itu, konsep ketersampaian dalam kajian ini merujuk kepada liputan perkhidmatan bas awam di beberapa laluan utama menghala ke pusat bandar Kota Kinabalu yang dapat memberi peluang kepada penduduk mengakses bas awam dengan mudah dan melibatkan diri dalam menjalankan aktiviti sosial harian.

Jadual 1. Konsep ketersampaian

\begin{tabular}{ll}
\hline Sarjana & Kata Kunci \\
\hline Handy (1994) & $\begin{array}{l}\text { Pengangkutan awam dapat meningkatkan mobiliti sosial masyarakat setempat } \\
\text { dan ke arah penciptaan peluang ekonomi yang aktif }\end{array}$ \\
Couclelis (2000) & $\begin{array}{l}\text { Meningkatkan akses perhubungan dalam segala aspek dalam kehidupan. } \\
\text { Geurs dan Wee (2004) }\end{array}$ \\
Sistem pengurusan guna tanah dengan pengangkutan awam harus selari \\
Carruthers (2005) & Persekitaran pengangkutan awam \\
Rodrigue et al,. (2006) & Elemen utama dalam geografi pengangkutan adalah untuk melihat sesuatu \\
& fenomena pergerakan manusia, pengangkutan dan maklumat dari pelbagai ruang \\
Farringhton (2007) & Hubungan di antara guna tanah, individu dan sistem pengangkutan awam \\
Abreha (2007) & Peluang untuk pergerakan \\
Bocarejo (2012) & Peluang untuk berinteraksi dalam aktiviti sosial harian \\
Litman (2013) & Anjakan paradigma lama fokus kepada pendekatan berteraskan mobiliti kepada \\
& paradigma baru memfokuskan kepada pendekatan berteraskan ketersampaian) \\
Kee (2016) & Kebebasan dalam memilih perkhidmatan pengangkutan awam \\
\hline
\end{tabular}

\section{Faktor-faktor mempengaruhi ketiadaan bas awam (pengangkutan awam)}

i) Faktor pihak berkuasa dan bertanggungjawab

Menerusi kajian yang dilakukan oleh Litman (2016) proses pengaturan sistem pengangkutan awam yang bergerak secara sistematik akan menyebabkan segala aktiviti sosial di zaman modenisasi ini akan dapat bergerak dengan lancar. Kelancaran sistem pengangkutan awam dapat membantu meningkatkan keberkesanan dan memaksimumkan ketersampaian penduduk dari satu lokasi ke lokasi yang lainnya. Dalam masa yang sama akan memudahkan pihak kerajaan agar terus dapat memperkasakan sistem polisi yang berterusan yang dilaksanakan secara berperingkat. Implikasi pengurusan pengangkutan awam yang berkesan akan 
membantu dalam memberikan mutu dan kualiti sistem pengangkutan awam bersifat secara lebih menyeluruh dan holistik.

Perancangan pembangunan pengangkutan awam perlu dijalankan berasaskan konsep analisis berorentasikan mobiliti (mobility-oriented analysis) yang bermaksud lebih memfokuskan kepada jangkauan sistem pengangkutan yang bersistematik tinggi untuk pergi ke sesuatu lokasi. Namun pada masa kini perancang polisi juga harus mengambil kira pendekatan berasaskan ketersampaian (accessibility based approach) merujuk kepada sistem pengangkutan yang melaksanakan tindakan pengurusan pengangkutan awam dengan menyediakan segala keperluan dalam usaha untuk menjalankan segala aktiviti perjalanan ke sesuatu destinasi dengan lebih berkesan (Litman, 2016).

Dalam konteks kajian Verseckiene et al. (2016) di Vilnius, Lithuania, kajiannya meneliti ketersampaian pengangkutan awam dalam kalangan golongan Orang Kurang Upaya (OKU) yang mendapati pengurusan sistem pengangkutan awam yang lemah menyebabkan masalah berlaku dalam sistem pengangkutan awam dalam kelompok masyarakat yang mendiami di kawasan bandar Vilnius. Tambahan pula terdapat pelbagai aspek lainnya yang turut menyumbang kepada masalah pengangkutan awam seperti kurangnya pemantauan dan kepedulian berkenaan dengan situasi pengangkutan awam semasa yang berlaku dalam kalangan pihak berkuasa. Selain itu, kurangnya perhatian pihak berkuasa dalam sektor pengangkutan awam menyebabkan permasalahan berkenaan dengan pengangkutan awam berlaku.

Manakala dalam kajian Preston dan Raje (2007) mendapati bahawa rangkaian sistem maklumat pengangkutan awam yang kurang jelas menyebabkan masalah dalam pengangkutan awam terus berlaku yang dianggap sebagai social exclusion yang terus menyebabkan kesukaran penduduk untuk mendapatkan maklumat yang tepat berkenaan dengan sistem pengangkutan awam yang disediakan kepada mereka. Hal ini disebabkan oleh terdapat beberapa laluan di Bristol, Nottingham, dan Oxfordshire, United Kingdom tiada kemudahan pengangkutan awam kepada penduduk.

Daripada perspektif yang berbeza Boisjoly dan El-Geneidy (2017) memperincikan bahawa terdapat pelbagai jenis faktor yang mendorong kepada masalah dalam memastikan darjah ketersampaian pengangkutan awam berlaku antara satu kawasan dengan kawasan yang lainnya, antaranya adalah perancangan pengangkutan awam yang tidak holistik dan kurangnya kepekaan tentang tanggungjawab meningkatkan kemajuan dalam bidang pengangkutan awam. Cabaran-cabaran tersebut menyebabkan perancang pengangkutan awam atau perancang guna tanah tidak dapat melaksanakan pendekatan berasaskan ketersampaian dalam perancangan pengangkutan awam.

Walau bagaimanapun Guzman dan Oviedo (2018) berpandangan bahawa pengaruh dan kesan subsidi amat mempengaruhi kelancaran sistem pengangkutan awam di Bandar Bogota dan Soacha, Colombia. Dengan pemberian bantuan tersebut akan dapat membantu dalam meningkatkan penggunaan dalam kalangan penduduk terhadap pengangkutan awam. Hal ini dapat dibuktikan menerusi kajian ini yang mana golongan miskin berpeluang untuk mengakses sistem pengangkutan ke mana sahaja yang hendak mereka tujui kerana tambang yang murah.

Dengan kata lain kajian menerusi Taylor dan Fink (2003) serta Harifah (2015) berpandangan bahawa terdapat faktor dalaman dan luaran yang mendorong penggunaan pengangkutan awam dalam kalangan penduduk. Faktor ini sebenarnya berlaku dalam karenah penggunaan pengangkutan awam dalam kalangan penduduk. Dalam konteks faktor dalaman ia menjurus perkara dalaman yang berlaku dalam dimensi sesebuah organisasi pengangkutan awam yang terkait dengan polisi, sistem pengurusan, pentadbiran dan segala hal berkaitan dengan kewangan. Manakala faktor luaran pula menjurus kepada faktor 
geografi, demografi dan sosioekonomi penduduk seperti pendapatan per kapita penduduk (Rajah 1).

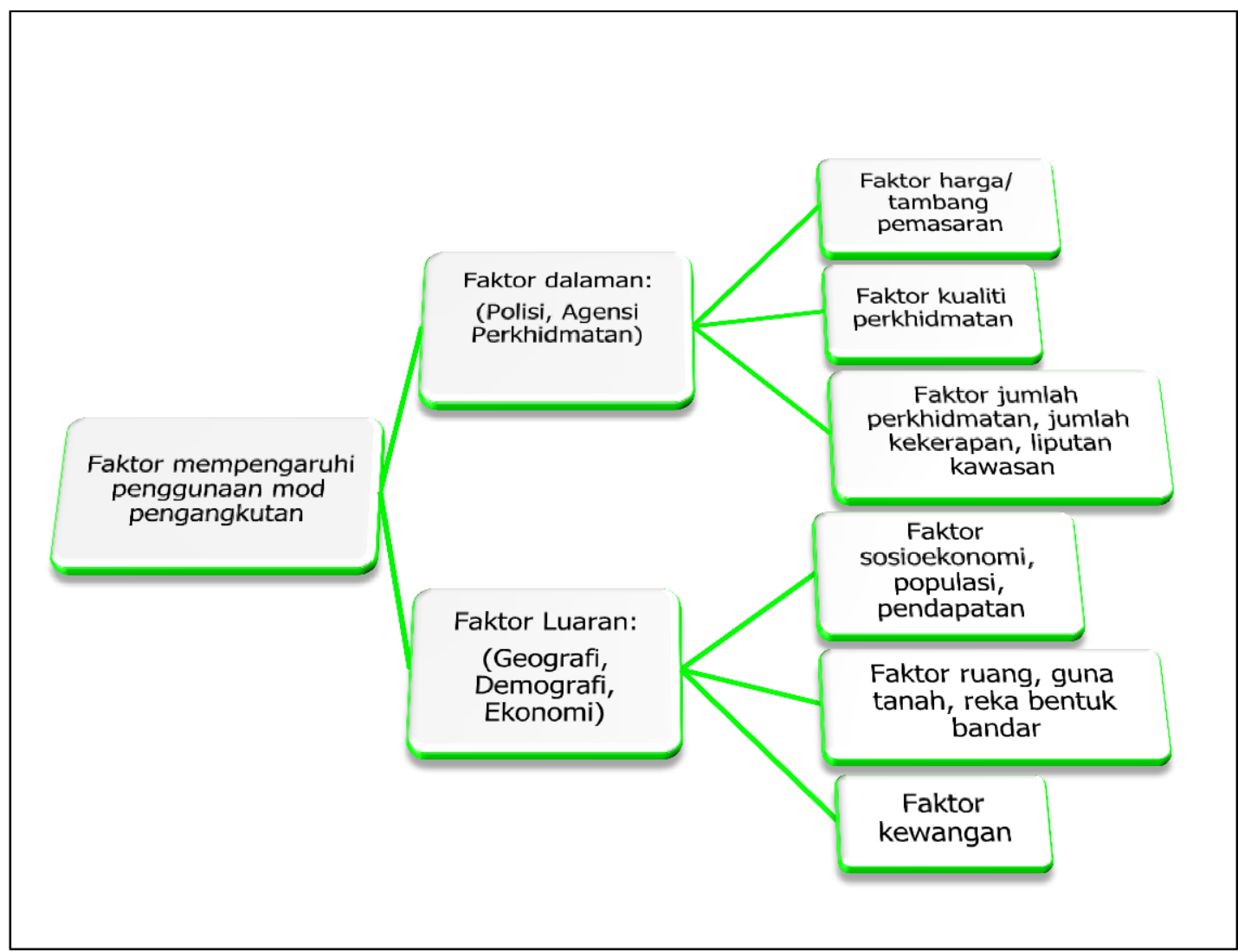

Sumber: Ubahsuai dari Taylor dan Fink , 2003; Harifah, 2015

Rajah 1. Diubah suai dan disesuaikan faktor yang mempengaruhi penggunaan mod pengangkutan

ii) Faktor pengusaha bas awam

Noor Ashikin et al. (2015) berpandangan kualiti dan mutu pengangkutan bas bandar di Bandaraya Kuala Terengganu berada pada tahap yang rendah. Kajian ini berpendapat bahawa pemandu bas awam seharusnya peka dengan keperluan semasa untuk menarik lebih ramai pelancong untuk menggunakan bas bandar. Oleh yang demikian, pengusaha bas seharusnya lebih profesional dalam menjalankan tanggungjawab sebagai pengusaha yang menyediakan perkhidmatan pengangkutan bas awam yang baik seperti memberikan layanan yang baik, menepati masa dan memberikan perkhidmatan yang terbaik. Namun dapatan tersebut sedikit berbeza dengan Mazdi et al. (2014) merumuskan bahawa kemudahan bas yang agak usang memberikan permasalahan kepada penumpang terutamanya pelajar sekolah untuk sampai ke sekolah SMK Seri Tapah dan SMK Tapah pada setiap hari dari kediaman pelajar tersebut.

Harifah et al. (2016) menyimpulkan kekerapan bas mini lebih kerap berbanding dengan pengangkutan awam lain menyebabkan bas mini mendominasi di Bandaraya Kota Kinabalu. Ini kerana ketersampaian pengangkutan awam lain hanya berfokus di kawasankawasan tertentu sahaja. Dalam konteks kajian Siti Nurbaya (2016) berpandangan bahawa masalah sistem pengangkutan awam memberikan permasalahan secara langsung dan tidak langsung terhadap perkembangan sistem pengangkutan awam di Kuala Lumpur. Antara permasalahan tersebut adalah seperti ketidakseimbangan permintaan bas pada waktu kemuncak keadaan ini menyebabkan masalah pengangkutan awam terus berlaku dan 
akhirnya ia memberikan implikasi yang tidak baik kepada mutu dan kualiti perkhidmatan pengangkutan jika ia tidak dapat diatasi dengan segera.

Dalam kajian lain yang dilakukan oleh Harifah et al. (2017) mendapati bahawa terdapatnya kekurangan dalam sistem pengangkutan awam di Kota Kinabalu kerana terdapatnya isu-isu yang belum mendapat penyelesaian yang sewajarnya. Antaranya isu adalah sistem pengurusan masa, kekurangan bas pada waktu kemuncak, hal ini ditambah pula dengan masalah ketidakseragaman perkhidmatan bas di satu lokasi di kawasan bandar.

\section{iii) Faktor penduduk}

Ibarra et al. (2017) menyatakan bahawa pertambahan jumlah populasi penduduk menyebabkan masalah permintaan dan penawaran perkhidmatan bas awam tidak seimbang wujud. Hal ini kerana jumlah bas awam yang sedikit menyukarkan penduduk mendapatkan peluang menikmati perkhidmatan bas yang sistematik. Dalam pembangunan dan perancangan sistem pengangkutan awam seharusnya mengambil kira pelbagai aspek dalam konteks pengurusan guna tanah, perancangan dan pembinaan jaringan sistem pengangkutan awam yang strategik. Dalam konteks lainnya para pengurus sistem pengangkutan awam perlu memperbanyakkan perkhidmatan pengangkutan bas awam di lokasi yang mempunyai banyak permintaan bas awam.

Hal ini turut diperkukuhkan dalam kajian yang dibuat oleh Bocarejo dan Oviedo (2012), dalam kajiannya mendapati bahawa kawasan permintaan pengangkutan awam terbahagi kepada beberapa kategori iaitu bergantung kepada struktur ekonomi bermula daripada yang berpendapatan rendah sehinggalah kepada berpendapatan tinggi. Manakala dalam kalangan penduduk yang berpendapatan tinggi lazimnya tidak memerlukan perkhidmatan bas awam, kerana kemampuan untuk memiliki kenderaan sendiri. Namun berbeza pula kepada masyarakat yang berpendapatan rendah golongan tersebut sangat memerlukan perkhidmatan bas awam kerana tiada pengangkutan kenderaan sendiri dan tambang bas awam berpatutan. Namun impak pembangunan yang tidak seimbang menyebabkan penduduk sukar untuk mengakses ke lokasi yang dituju. Hal ini bersangkut paut dengan tahap ketersampaian pengangkutan awam masih tidak mencapai tahap yang maksimum serta menyukarkan mobiliti golongan tersebut untuk melakukan aktiviti sosial harian terutama sekali untuk perjalanan ulang alik penduduk ke tempat kerja. Johnson et al. (2017) berpandangan bahawa golongan masyarakat yang berpendapatan tinggi lazimnya lebih gemar untuk memiliki kenderaan sendiri untuk sampai ke sesuatu tempat yang hendak ditujui, namun hal ini berbeza dengan penduduk yang berpendapatan rendah menggunakan sepenuhnya perkhidmatan bas awam untuk sampai ke sesuatu lokasi yang dituju.

\section{Metod dan kawasan kajian}

Teknik pengumpulan maklumat menerusi berasaskan sumber primer dan sumber sekunder digunakan dalam kajian ini. Antara kaedah sumber primer digunakan kajian ini adalah pemerhatian langsung di sembilan laluan utama bas awam yang terdiri daripada bas mini, bas henti-henti, bas bandar menuju ke Bandaraya Kota Kinabalu. Antaranya adalah di laluan Tuaran, Sepanggar, Inanam, Tuaran By Pass, Lintas, Putatan, Penampang, Tanjung Aru dan Bukit Padang. Pemerhatian langsung dijalankan untuk melihat ketersampaian perkhidmatan bas awam di laluan utama (Ranjit, 2011). Pemerhatian langsung dilakukan untuk meneliti darjah ketersampaian bas awam kepada penduduk daripada pukul lapan pagi sehingga lima petang di laluan utama tersebut. Di samping itu, temu bual mendalam secara semi struktur 
dilakukan dengan informan kajian untuk mendapatkan pandangan informan tentang isu kajian ini.

Sementara itu kajian ini menggunakan pendekatan tinjauan keratan rentas (crosssectional) dengan mengedarkan borang soal selidik sekali sahaja dalam satu tempoh tertentu, tetapi terhadap kumpulan orang yang berbeza untuk mendapatkan data statistik yang bersifat deskriptif berkaitan dengan kajian ini (Othman, 2013). Kajian ini menggunakan pensampelan bertujuan sebanyak 274 responden yang terdiri daripada pengguna bas awam di laluan Tuaran By Pass dan Lintas ke pusat Bandaraya Kota Kinabalu. Satu set borang soal selidik diserahkan kepada responden dengan menggunakan skala lima likert seperti "sangat tidak setuju", "tidak setuju", "kurang pasti", "setuju" dan "sangat setuju" untuk mendapatkan persepsi responden terhadap maklumat ketersampaian perkhidmatan bas awam ke Bandaraya Kota Kinabalu.

Pemprosesan dan analisis data dengan menggunakan Statistical Package for the Social Sciences (SPSS) versi 20 dan analisis menggunakan statistik deskriptif iaitu analisis frekuensi dan skor min. Dalam kajian ini untuk menginterpretasikan skor min menggunakan skor min diketengahkan oleh Jamil (2002) iaitu skor 1.00 hingga 2.33 menunjukkan nilai min pada tahap rendah, sementara skor 2.34 hingga 3.66 nilai min pada tahap sederhana, dan akhir sekali skor min 3.67 hingga 5.00 nilai min yang tinggi.

Bandaraya Kota Kinabalu merupakan ibu negeri Sabah yang mempunyai keluasan 352.10 kilometer persegi $(\mathrm{km} 2)$. Kawasan ini bersempadan dengan beberapa daerah seperti Putatan, Tuaran, Penampang. Dari segi lokasinya ia teletak di antara longitud $116^{\circ} 1$ ' 0 " $116^{\circ} 16^{\prime} 0$ " T dan latitud 5 51'30" - 6 4' 30" U (Rajah 2). Kota Kinabalu merupakan pintu masuk negeri Sabah yang bersempadan dengan daerah Penampang, Putatan dan Tuaran. Kota Kinabalu adalah Central Business District (CBD) dari perspektif ilmu geografi kerana kawasan ini menjadi tumpuan masyarakat sekitarnya untuk menjalankan pelbagai aktiviti sosial harian. Hal ini disebabkan Kota Kinabalu merupakan satu kawasan yang membangun dengan pesat sebagai One Stop Centre City yang mempunyai pelbagai fungsi kepada penduduk setempat dan antarabangsa.

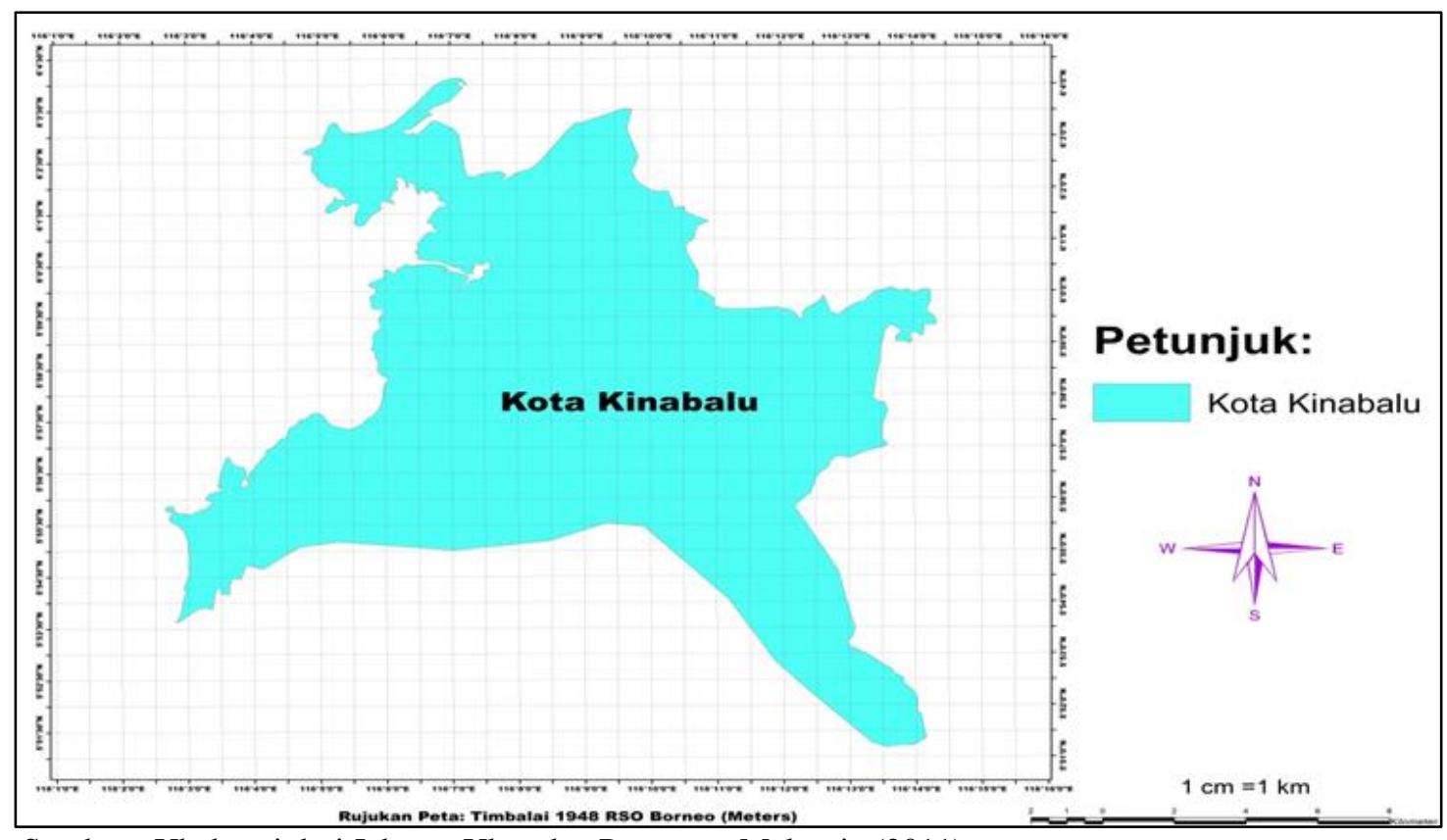

Sumber: Ubahsuai dari Jabatan Ukur dan Pemetaan Malaysia (2011)

Rajah 2. Kawasan kajian 


\section{Hasil kajian dan perbincangan kajian}

\section{Ciri-ciri demografi responden}

Jadual 2 menunjukkan majoriti responden merupakan golongan perempuan sebanyak 55 peratus manakala golongan lelaki sebanyak 45 peratus. Kebanyakan responden bekerja sepenuh masa sebanyak 73.3 peratus dan diikuti bekerja separuh masa sebanyak 16.8 peratus serta golongan pelajar sebanyak 9.9 peratus. Majoriti responden berumur lebih daripada 21 tahun sebanyak 80 peratus manakala yang minoriti adalah golongan berumur 36 tahun ke atas sebanyak lima peratus. Kebanyakan responden berpendapatan bulanan adalah kurang daripada RM 1500 sebanyak 78.6 peratus manakala responden berpendapatan bulanan yang paling tinggi adalah lebih daripada RM 2001 sebanyak 4.6 peratus. Ini menunjukkan taraf hidup responden dalam kajian ini terdiri daripada kategori sederhana dan rendah. Majoriti responden terdiri daripada etnik Dusun sebanyak 31.3 peratus manakala etnik lain-lain terdiri daripada Rungus, Brunei, India, Sinokadazan, Banjar, Sungai, Iban, Bisaya dan Iranun sebanyak 10.7 peratus.

Jadual 2. Demografi responden

\begin{tabular}{llll}
\hline Bil & Item & Kategori & Peratus (\%) \\
\hline 1 & Jantina & Lelaki & 45 \\
& & Perempuan & 55 \\
\hline 2 & Etnik & Melayu & 13 \\
& & Cina & 9.2 \\
& & Kadazan & 10.7 \\
& & Dusun & 31.3 \\
& & Bajau & 19.8 \\
& & Bugis & 5.3 \\
\hline 3 & Umur & Lain-lain & 10.7 \\
& & $<20$ & 15 \\
& & $21-25$ & 42 \\
& & $26-30$ & 28 \\
& & $31-35$ & 10 \\
& & $36-40$ & 4 \\
& & $41>$ & 1 \\
\hline 4 & Status pekerjaan & Bekerja (sepenuh masa) & 73.3 \\
& & Bekerja (separuh masa) & 16.8 \\
& & Pelajar & 9.9 \\
\hline 5 & Pendapatan bulanan & RM 800 & 28.2 \\
& & RM 801 - RM 1500 & 50.4 \\
& & RM 1501 - RM 2000 & 6.9 \\
& & RM 2001 > & 4.6 \\
& & Lain-lain (pelajar) & 9.9 \\
\hline & Jumlah & & 100 \\
\hline
\end{tabular}

Ciri-ciri penggunaan bas awam

Jadual 3 menunjukkan majoriti responden menggunakan bas awam lebih dari dua hingga empat kali dalam seminggu sebanyak 79 peratus manakala selebihnya menggunakan bas awam sekali dalam seminggu sebanyak 21 peratus. Kebanyakan responden menaiki dua buah bas awam untuk menuju ke pusat Bandaraya Kota Kinabalu iaitu sebanyak 64.5 peratus. Data ini membuktikan bahawa kebanyakan responden gemar menggunakan bas awam sebagai mod pengangkutan untuk sampai ke pusat bandar Kota Kinabalu. 
Jadual 3. Ciri-ciri penggunaan bas awam

\begin{tabular}{llll}
\hline Bil & Item & Kategori & Peratus (\%) \\
\hline 1 & Kekerapan bas digunakan dalam seminggu & Sekali seminggu & 21 \\
& & $2-4$ kali & 44.3 \\
& & $5-7$ kali & 28.2 \\
& & lebih 7 kali & 6.5 \\
\hline 2 & Bilangan bas dinaiki untuk mengakses ke & Satu & 35.5 \\
& pusat bandar & Dua & 64.5 \\
\hline & Jumlah & & 100 \\
\hline
\end{tabular}

Ketersampaian bas awam di laluan utama menuju ke pusat Bandaraya Kota Kinabalu

Berdasarkan Rajah 3 merujuk kepada kemudahan ketersampaian perkhidmatan laluan bas awam di laluan utama ke Bandaraya Kota Kinabalu daripada pelbagai arah perjalanan seperti Tuaran, Sepanggar, Inanam, Bukit Padang, Putatan, Penampang, Tanjung Aru kecuali di laluan Tuaran By Pass dan Lintas (sila rujuk tanda warna hijau dalam Rajah 3). Namun, di laluan Lintas dan Tuaran By Pass terdapat beberapa kemudahan awam kepada penduduk Kota Kinabalu. Misalnya di laluan Tuaran By Pass terdapat kawasan perumahan Tuaran By Pass dan SMK Bandaraya Manakala di laluan Lintas pula terdapat kemudahan pusat membeli belah, SJK Cina Che Hwa Kolombong, pasar basah AM PM, Borneo Sports Arena, taman perumahan, zon perindustrian dan Jesselton Medical Centre. Ketiadaan perkhidmatan pengangkutan awam terutama sekali bas awam menyebabkan golongan yang tiada mempunyai kenderaan sendiri mengalami kesukaran untuk sampai ke pusat bandar untuk menjalankan aktiviti sosial harian. Hal ini demikian kerana terdapat beberapa faktor dalaman dan luaran yang menyebabkan masalah ketiadaan bas awam beroperasi di laluan Lintas dan Tuaran By Pass terkait dengan sistem pengurusan pengangkutan awam yang tidak bersifat holistik (Jadual 4).

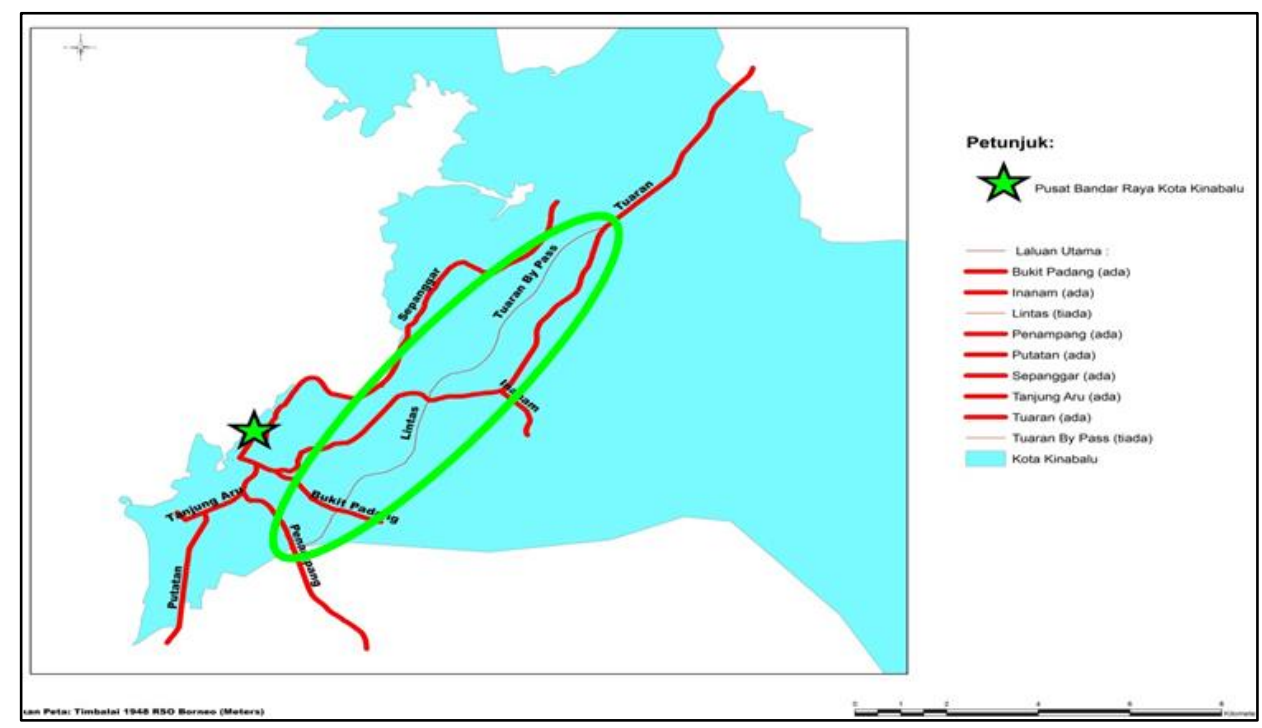

Rajah 3. Ketersampaian perkhidmatan bas awam menuju ke Bandaraya Kota Kinabalu 


\section{Faktor-faktor ketiadaan bas awam di Laluan Tuaran By Pass dan Lintas}

Berdasarkan Jadual 4 analisis kajian mendapati bahawa faktor pengusaha bas menduduki nilai min keseluruhan yang tinggi 3.01 berbanding penduduk 2.90 dan Pihak Berkuasa Tempatan (PBT) 2.83. Ini menunjukkan bahawa terdapatnya masalah dalam konteks pengurusan dan pentadbiran pengangkutan awam yang tidak dijalankan secara holistik. Maklumat Jadual 4 menunjukkan ketiga-tiga faktor berada pada tahap yang sederhana dan perlu dititikberatkan serta penambahbaikan daripada pihak-pihak yang bertanggungjawab agar kualiti hidup penduduk terjamin dan mencipta situasi menang-menang kepada semua pihak-pihak berkepentingan yang terlibat dalam perancangan bas awam seperti pengusaha bas dan PBT serta pihak yang menggunakan perkhidmatan bas awam iaitu penduduk di kawasan ini.

Jadual 4. Faktor-faktor ketiadaan bas awam di laluan Lintas dan Tuaran By Pass

\begin{tabular}{|c|c|c|c|}
\hline Faktor & Item & Min & $\begin{array}{l}\text { Min } \\
\text { keseluruhan }\end{array}$ \\
\hline \multirow{4}{*}{ Pengusaha Bas } & $\begin{array}{l}\text { Pengusaha bas tidak beroperasi di } \\
\text { laluan ini }\end{array}$ & 3.09 & \multirow{4}{*}{3.01} \\
\hline & Laluan tidak menguntungkan & 3.21 & \\
\hline & Laluan kekurangan penumpang & 2.91 & \\
\hline & $\begin{array}{l}\text { Belum mendapatkan lesen } \\
\text { perkhidmatan }\end{array}$ & 2.82 & \\
\hline \multirow[b]{4}{*}{ Penduduk } & Masyarakat guna kenderaan sendiri & 3.32 & \multirow[b]{4}{*}{2.90} \\
\hline & Faktor pendapatan yang tinggi & 2.89 & \\
\hline & Tiada permintaan bas oleh penduduk & 2.79 & \\
\hline & Kurang penghuni di laluan ini & 2.62 & \\
\hline \multirow{4}{*}{$\begin{array}{l}\text { Pihak Berkuasa } \\
\text { Tempatan (PBT) }\end{array}$} & $\begin{array}{l}\text { Lesen perkhidmatan belum } \\
\text { dikeluarkan }\end{array}$ & 2.82 & \multirow{4}{*}{2.83} \\
\hline & Pengusaha bas tidak mematuhi laluan & 3.01 & \\
\hline & $\begin{array}{lcc}\text { Kurang kakitangan } & \text { memantau } \\
\text { perkhidmatan pengusaha } & \end{array}$ & 2.76 & \\
\hline & $\begin{array}{lcc}\text { Kurangnya penekanan akan } \\
\text { kepentingan melalui laluan ini }\end{array}$ & 2.72 & \\
\hline
\end{tabular}

Faktor penduduk merupakan faktor luaran memberikan permasalahan dalam sistem pengangkutan bas awam, hal ini kerana jika sesuatu kawasan mempunyai penduduk yang berpendapatan tinggi maka hal ini akan memberikan tekanan kepada golongan minoriti yang memerlukan perkhidmatan bas awam. Seperti dalam kajian Johnson et al. (2017) di bandar London dan Guzman dan Oviedo (2018) di bandar Bogota dan Soacha. Keadaan yang sama juga berlaku di Lintas dan Tuaran By Pass melalui pemerhatian kajian ini mendapati kebanyakan penduduk di laluan ini mempunyai kenderaan sendiri seperti kereta dan motosikal untuk sampai ke pusat bandar tetapi golongan berpendapatan sederhana dan rendah di kawasan ini bergantung dengan bas awam untuk sampai ke pusat bandar. Golongan tersebut merupakan golongan yang minoriti memerlukan perkhidmatan bas awam di kawasan ini dan permintaan dalam komuniti tersebut sedikit menyebabkan keuntungan yang sedikit diperolehi oleh pengusaha bas serta ini menyebabkan sesetengah pengusaha bas tidak melalui di laluan ini (Informan satu). Ia terbukti dengan data kajian ini (Jadual 2 dan Jadual 3) responden yang menggunakan bas awam merupakan golongan berpendapatan bulanan RM 1500 ke bawah dan menggunakan bas awam dua hingga empat kali dalam seminggu ke pusat bandar Kota Kinabalu. Melalui Jadual 3 mendapati pengguna mengambil dua buah bas untuk sampai ke pusat bandar dan keadaan ini sudah pasti meningkatkan kos sara hidup pengguna bas awam di kawasan ini. 
Manakala dalam konteks faktor dalaman masalah pengusaha bas yang enggan melalui kawasan ini kerana kurang permintaan dan faktor mengejar keuntungan dalam kalangan pengusaha bas. Pengusaha bas beranggapan bahawa di laluan Tuaran By Pass dan Lintas sangat kurang permintaan menyebabkan pengusaha bas enggan pergi ke tempat tersebut untuk memberikan perkhidmatan bas awam. Maklumat ini bertepatan dengan Bocarejo dan Oviedo (2012) di bandar Bogota, Colombia di mana permintaan golongan berpendapatan sederhana dan rendah yang menggunakan pengangkutan awam dalam kuantiti sedikit menyebabkan penawaran pengangkutan awam turut rendah kerana permintaan daripada golongan minoriti yang akan mempengaruhi keuntungan pengusaha bas. Namun demikian tidak boleh dipersalahkan pengusaha bas dalam keadaan ini semata-mata kerana kos sara hidup yang tinggi pada masa kini menyebabkan pengusaha bas harus menitikberatkan aspek keuntungan melalui perkhidmatannya untuk survival hidup pengusaha bas. Ini disebabkan tiada ada satu sistem pengangkutan awam yang holistik yang mengambil kira kebajikan semua pihak di kawasan ini menyebabkan keadaan sebegini berlaku di laluan ini.

Pengaruh daripada PBT memberikan kesan langsung dan tidak langsung kepada pengurusan sistem pengangkutan yang berkesan dan bersifat holistik, hal ini kerana pihak berkuasa tempatan membantu menjalankan pemeriksaan yang sistematik terhadap isu dan perkembangan berkenaan sistem pengangkutan awam dengan menjalankan kajian, penelitian berkenaan dengan isu-isu yang terkait dengan kualiti dan mutu perkhidmatan pengangkutan awam di sesuatu kawasan misalnya PBT harus peka dengan keperluan penduduk di laluan Lintas dan Tuaran By Pass. Hal ini diperkukuhkan dalam kajian Preston dan Raje (2007) di Bristol, Nottingham, dan United Kingdom.

Sehubungan dengan itu, PBT perlu melaksanakan pendekatan bottom up untuk mengatasi masalah ini daripada terus berlaku. Antara langkah yang perlu dijalankan adalah dengan melaksanakan program subsidi kepada pengusaha bas supaya pengusaha bas lebih bermotivasi untuk memberikan perkhidmatan sistem pengangkutan awam dengan lebih baik di kawasan ini. Sebagaimana yang dijelaskan oleh Guzman dan Oviedo (2018) berpandangan bahawa pemberian subsidi mampu mengatasi masalah beban kewangan dalam kalangan pengusaha bas.

Di samping itu, untuk menyelesaikan isu berkenaan dengan sistem pengangkutan awam dalam kalangan pihak yang berwajib perlu mengambil kira idea seperti yang telah dicadangkan oleh Ketua Seksyen Pengangkutan Awam JKR Sabah (Informan dua). Antara cadangan beliau adalah ke semua sistem pengangkutan awam perlu dikawal selia oleh kerajaan secara berpusat dalam usaha untuk memastikan sistem pengurusan dan pentadbiran pengangkutan awam dapat diseragamkan di Bandaraya Kota Kinabalu. Hal ini dapat menyelesaikan masalah dalam pengurusan sistem perkhidmatan pengangkutan awam bersifat persendirian yang berlaku pada masa kini di Bandaraya Kota Kinabalu, jika ia terus berlaku ia akan mengganggu proses pengurusan pengangkutan awam secara sistematik dan bersifat holistik pada masa sekarang serta masa hadapan.

Seterusnya, dalam kajian ini mendapati bahawa dalam usaha untuk menyelesaikan masalah ini daripada terus berlaku maka pendekatan Tanaka (2014) iaitu pendekatan Demand Responsive Transport (DRT) adalah amat bersesuaian untuk digunakan dalam menyelesaikan masalah ini daripada terus berlaku. Hal ini kerana pendekatan ini telah terbukti dan berjaya secara empirikal dalam menyelesaikan masalah berkenaan dengan sistem pengangkutan awam di Jepun. Jika pendekatan ini dapat diaplikasikan secara sepenuhnya ia akan dapat menyelesaikan masalah sistem pengangkutan awam di laluan Tuaran By Pass dan Lintas.

Berdasarkan kepada penemuan Boisjoly dan El-Geneidy (2017) pengurusan sistem pengangkutan awam yang kurang berkesan menyebabkan masalah dalam sistem pengangkutan awam terus berlaku. Hal ini bersamaan dengan situasi seperti yang terdapat dalam kajian yang dilakukan misalnya isu dalam sistem pengangkutan awam seharusnya 
mendapat perhatian daripada pelbagai pihak yang bertanggungjawab dalam usaha untuk memberikan perkhidmatan pengangkutan awam yang baik kepada masyarakat.

Secara keseluruhannya, pihak-pihak yang bertanggungjawab hendaklah menjalankan tanggungjawab secara efektif dan efisien dalam menyelesaikan isu yang terkait dengan masalah sistem pengangkutan awam di kawasan ini. Bukan sahaja menitikberatkan aspek luaran tetapi juga mementingkan penyelesaian terhadap masalah dalaman yang berlaku dalam sistem pengangkutan awam. Segala usaha praktikal dan penentuan polisi serta penggubalan polisi sistem pengangkutan awam perlu dijalankan dari masa ke semasa dalam usaha untuk memperbaiki dan menyelesaikan masalah dalam pengurusan sistem bas awam yang berkesan agar ketersampaian pengguna terhadap bas awam ditingkatkan.

\section{Kesimpulan}

Ketersampaian pengangkutan awam terutama sekali bas awam amat penting untuk seseorang pengguna atau penduduk untuk sampai dari satu tempat ke tempat yang lainnya. Namun dalam konteks perjalanan sistem pengangkutan awam di Kota Kinabalu terdapat beberapa laluan khusus yang tidak mempunyai kemudahan sistem perkhidmatan bas yang baik seperti di laluan Tuaran By Pass dan Lintas. Ia secara tidak langsung memberi kesan kepada kualiti hidup penduduk di laluan tersebut. Implikasi daripada masalah sistem pengangkutan awam ini menyebabkan masalah ketersampaian berlaku maka dengan itu semua pihak-pihak yang bertanggungjawab dalam perkhidmatan pengangkutan bas awam seharusnya bersatu dalam usaha untuk memberikan perkhidmatan yang terbaik kepada masyarakat di kawasan ini. Implikasi kajian ini sangat berguna kepada perancang pengangkutan awam di Kota Kinabalu supaya menekankan indikator berteraskan ketersampaian apabila membuat sesuatu polisi atau dasar berkenaan pengangkutan awam secara umum dan khusus kepada bas awam agar perkhidmatan bas awam disediakan kepada penduduk Kota Kinabalu mesra pengguna dan sekali gus meningkatkan kualiti hidup penduduk Kota Kinabalu setanding dengan bandarbandar di peringkat tempatan dan antarabangsa.

\section{Rujukan}

Abreha, D.A. (2007). Analyzing public transport performance using efficiency measures and spatial analysis: The case of Addis Ababa. Tesis Sarjana (Tidak diterbitkan). Enschede, Netherlands: International Institute for Geo-Information Science and Earth Observation.

Armstrong, W.A., \& Sebastian, T. (1987). Bus services: reducing cost, raising standards. World Bank technical paper; no. WTP 68. Washington, DC: The World Bank. Retrieved from http://documents.worldbank.org/curated/en/572491468764379405/ Bus-services-reducing-costs-raising-standards

Bocarejo, S.J.P., \& Oviedo H.D.R. (2012). Transport accessibility and social inequities: a tool for identification of mobility needs and evaluation of transport investments. Journal of Transport Geography, 24, 142-154.

Boisjoly, G., \& El-Geneidy, A.H. (2017). The insider: A planners' perspective on accessibility. Journal of Transport Geography, 64, 33-43.

Carruthers, R.C., Dick, M.C., \& Saurkar, A. (2005). Affordability of public transport in developing countries. Transport Papers; no. TP-3. Washington, DC: World Bank.

Couclelis, H. (2000). From sustainable transportation to sustainable accessibility: can we avoid a new tragedy of the commons?. In: Janelle D.G., \& Hodge D.C. (eds), 
Information, Place, and Cyberspace. Advances in Spatial Science. Berlin, Heidelberg, Springer.

Farrington, J.H. (2007). The new narrative of accessibility: its potential contribution to discourses in (transport) geography. Journal of Transport Geography, 15(5), 319330.

Geurs, K.T, \& Wee, B.V. (2004). Accessibility evaluation of land-use and transport strategies: review and research directions. Journal of Transport Geography, 12(2), 127-140.

Guzman, L.A., \& Oviedo, D. (2018). Accessibility, affordability and equity: assessing 'propoor' public transport subsidies in Bogotá. Transport Policy, 68, 37-51. https://doi.org/10.1016/j.tranpol.2018.04.012

Handy, S. (1994). Highway Blues: Nothing a little accessibility can't cure. Berkeley. University of California Transportation Centre.

Harifah Mohd Noor, Ali Akbar, \& Jabil Mapjabil. (2017). Sistem dan isu pengangkutan awam Kota Kinabalu Sabah. Dlm. Mohammad Tahir Mapa, Ubong Imang \& Mustapa Abd. Talip. (Eds), Isu-isu alam sekitar dan manusia di Sabah kajian dari sudut pandang geografi (hlm 15-36), Tanjong Malim: Universiti Pendidikan Sultan Idris.

Harifah Mohd Noor. (2015). Keberkesanan dan Kualiti Perkhidmatan Bas di Kota Kinabalu. Bangi: Universiti Kebangsaan Malaysia. (Tesis PhD tidak diterbitkan).

Harifah Mohd Noor, Mazdi Marzuki, Jabil Mapjabil, \& Oliver Valentine Eboy. (2016). Keberkesanan perkhidmatan bas mini di Kota Kinabalu, Sabah. Geografia: Malaysian Journal of Society and Space, 12(12), 50-62.

Ibarra-Rojas, O.J., Hernandez, L., \& Ozuna, L. (2017). The accessibility vehicle routing problem. Journal of Cleaner Production, 135, 1514-1528. https://doi: 10.1016/j.jclepro.2017.10.249.

Johnson, D., Ercolani, M., \& Mackie, P. (2017). Econometric analysis of the link between public transport accessibility and employment. Transport Policy, 60, 1-9. https://doi.org/10.1016/j.tranpol.2017.08.001

Ahmad Jamil. (2002). Pemupukan budaya penyelidikan di kalangan guru di sekolah: satu penilaian. (Tesis PhD). Universiti Kebangsaan Malaysia.

Jabatan Ukur dan Pemetaan Malaysia. (2011). Negeri Sabah Bahagian Pantai Barat Daerah Kota Kinabalu.

Litman, T. (2013). The New Transportation Planning Paradigm. ITE Journal, 83(6): 20-28.

Litman, T. (2012). Evaluating accessibility for transportation planning: Measuring people's ability to reach desired goods and activities. Canada, Victoria Transport Policy Institute. Diakses melalui www.vtpi.org pada 17 March 2017.

Mazdi Marzuki, Jabil Mapjabil, \& Rosmiza, M.Z. (2014). Mengupas keciciran pelajar orang asli Malaysia: Suatu tinjauan ke dalam isu aksesibiliti sekolah. Geografia: Malaysian Journal of Society and Space, 10(2), 189-198.

Noor Ashikin, Mazdi Marzuki, \& Jabil Mapjabil. (2015). Persepsi penduduk tempatan dan pelancong terhadap isu perkhidmatan bas bandar sebagai pengangkutan pelancongan. Dlm. Mazdi Marzuki, \& Jabil Mapjabil. (Pnyt.), Isu-Isu Pengangkutan Darat Di Malaysia. Batu Pahat: Universiti Tun Hussein Onn Malaysia. Hlm 65-85.

Othman Talib. (2013). Tulis tesis cepat teknik efektif dan efisyen. Bangi: MPWS Rich Resources.

Preston, J., \& Raje, F. (2007). Accessibility, mobility and transport-related social exclusion. Journal of Transport Geography, 15(3), 151-160.

Ranjit, K. (2011). Research Methodology A Step By Step Guide For Beginners ( ${ }^{\text {rd }}$ Ed.). London: Sage Publications Ltd. 
Rodrigue, J.P., Comtois, C., \& Slack, B. (2006). The geography of transport systems. New York: Routledge.

Siti Nurbaya, A.K. (2016). Improving Quality of Rail Service in Kuala Lumpur, Malaysia. Faculty of Engineering and The Environment: University Of Southampton. (Tesis $\mathrm{PhD}$ tidak diterbitkan).

Tanaka, K. (2014). Transport Geography in Japan. Journal of Transport Geography, 34, 305306.

Taylor, B.D., \& Fink, C.N.Y. (2003). The factor influencing transit ridership: a review and analysis of the ridership literature. Los Angeles: UCLA Institute of Transportation Studies.

Unit Perancang Ekonomi. (2015). Rancangan Malaysia Kesebelas 2016-2020 - Pertumbuhan berpaksikan rakyat (RMK-11). Kuala Lumpur: Percetakan Nasional Malaysia Berhad.

Verseckienè, A., Meškauskas, V., \& Batarlienè, N. (2016). Urban public transport accessibility for people with movement disorders: The case study of Vilnius. Procedia Engineering, 134, 48-56.

Wee, Bert van. (2016). Accessible accessibility research challenges. Journal of Transport Geography, 51, 9-16. https://doi.org/10.1016/j.jtrangeo.2015.10.018

White, P.R. (2002). Public Transport: Its planning, Management and Operation. New York: Routledge. 